\section{Neuronas y valores}

\section{Amadeo Muntané-Sánchez}

Sección de Neurorradiología. Servicio de Radiología. Hospital General Universitari de Bellvitge. L'Hospitalet de Llobregat, Barcelona, España.

Correspondencia: Dr. Amadeo Muntané Sánchez. Sección de Neurorradiología. Servicio de Radiología. Hospital General Universitari de Bellvitge. Feixa Llarga, s/n. E-08907 L'Hospitalet de Llobregat (Barcelona).

E-mail: amuntane@bellvitgehospital.cat

Aceptado: 09.10.13.

Cómo citar este artículo: Muntané-Sánchez A.

Neuronas y valores [carta]. Rev Neurol 2014; 58: 48

(c) 2014 Revista de Neurología

A raíz de la reciente publicación del artículo de Camps en Revista de Neurología [1], cabe decir que ciertamente la neurociencia ha experimentado un gran desarrollo en las últimas décadas poniendo de relieve no sólo la complejidad del cerebro, sino la relación existente entre las funciones cognitivas, afectivo-emocionales y sensoriales con el sustrato neurobiológico. La investigación cerebral ha tocado de lleno lo que se considera más esencial de la persona humana: los pensamientos, las emociones y la libertad. En efecto, la investigación neurológica puede transformar de forma radical nuestra imagen del hombre y consecuentemente el fundamento de nuestra cultura, la base de nuestras decisiones éticas y políticas.

La descripción de trastornos de la conducta moral en pacientes con lesiones cerebrales explica el surgimiento de la neurociencia de la moral, cuyo objetivo es dilucidar los mecanismos neuronales y cognitivos de ésta. El análisis de las bases neurobiológicas de la moralidad se realiza mediante exámenes neuropsicológicos que abordan las alteraciones de las conductas éticas en pacientes con patología cerebral y mediante estudios que, utilizando resonancia magnética funcional, muestran las regiones cerebrales activadas durante la realización de tareas experimentales que involucran las capacidades morales [2]. Estos estudios revelan que la corteza prefrontal y sus múltiples conexiones con el sistema límbico, el tálamo y el tronco cerebral constituyen las estructuras nerviosas a las que se atribuyen las normas complejas y los valores morales $[3,4]$.

Ahora bien, a pesar de los avances científicos, no se sabe en realidad cómo funciona el cerebro de manera global en condiciones normales. El problema no radica en conocer qué regiones del cerebro y qué conexiones participan en la conducta moral de un individuo o en otras funciones. La clave es explicar cómo pasamos de las neuronas, sinapsis y ritmos cerebrales a fenómenos como la voluntad, la imaginación, el conocimiento, la abstracción, el raciocinio, el lenguaje y las capacidades sensitivas y sensoriales. Es cierto que el sustrato nervioso resulta necesario para que se den estos procesos y que la conducta humana cognitivo-emocional requiere la integración dinámica de múltiples áreas cerebrales [5]. También es evidente que las lesiones que afectan dicho sustrato pueden dar lugar a trastornos conductuales.

Pero no es menos cierto que no existe evidencia científica experimental que explique la continuidad fisiológica entre la neurobiología y estos fenómenos, es decir, qué ocurre exactamente en las redes neuronales para que desde los cambios iónicos, liberación de neurotransmisores, etc., podamos realizar un juicio moral con todo lo que supone esta elaboración: la consideración intelectiva en el obrar, la voluntariedad de ejercicio y el libre albedrío.

Efectivamente, reducir estas capacidades a un sistema neuronal hace muy difícil una comprensión coherente y satisfactoria de la propia conducta humana. Por ese motivo se ha rebatido recientemente la pretensión de buscar una ética universal basada en un sustrato cerebral [6].

Cuando Roentgen descubrió los rayos $X$ en 1895, no lo hizo porque los visualizara, dado que son invisibles, sino porque evidenció unos efectos o capacidades de estas ondas electromagnéticas. Por consiguiente, se podría formular una hipótesis que no sería de carácter mecanicista dualista y consistiría en considerar la presencia de un elemento, que de manera similar a los rayos $\mathrm{X}$ no estaría compuesto de átomos ni moléculas, al que se podría denominar $\alpha$. El elemento $\alpha$, todavía no identificado científicamente, sería intrínseco e integrado unitaria y funcionalmente al soporte neuronal y vicever- sa, de manera que la función resultante sería un acto único y no dos actos correlacionados; por tanto, lo propio de esta funcionalidad sería la unificación de la actividad neuroquímica cerebral y lo conocido de modo consciente mediante la transmisión de una información sofisticada y altamente procesada, de naturaleza desconocida, que subyace a la abstracción más intensa que requiere el pensamiento y la intención del ser humano. Esta unificación haría posible la toma de decisiones que se realiza en la conducta moral mediante lo que le es propio: reprocesar alternativas y elegir la óptima.

Según esta perspectiva, aunque la neurociencia permita descubrir y conocer todas las áreas cerebrales que participan en la conducta ética, hay que considerar que lo pensado no se relacionaría únicamente con la fenomenología molecular cerebral. Por consiguiente, la neurociencia por sí sola no puede explicar por qué se puede distinguir entre el bien y el mal o por qué no se hace el bien que se quiere y en cambio se hace el mal que no se quiere. Por ese motivo me parecería más apropiado hablar de interdisciplinariedad que de materialismo ilustrado. Un diálogo interdisciplinar profundo con la neurociencia no debe establecerse únicamente con la filosofía, sino con otros saberes como la psicología, la sociología, el derecho, las matemáticas, la informática, etc., de manera que se respete la variedad de los diferentes puntos de vista buscando las conexiones entre las diversas perspectivas que constituyen el entramado de la vida humana y la búsqueda de su sentido.

\section{Bibliografía}

1. Camps V. Neuronas y valores. Rev Neurol 2013; 57: 230-4.

2. Slachevsky A, Silva JR, Prenafeta ML, Novoa F. The contribution of neuroscience to the understanding of moral behavior. Rev Med Chil 2009; 137: 419-25.

3. Forbes $C E$, Grafman J. The role of the human prefrontal cortex in social cognition and moral judgment. Annu Rev Neurosci 2010; 33: 299-324.

4. Marazziti D, Baroni S, Landi P, Ceresoli D, Dell'osso L. The neurobiology of moral sense: facts or hypotheses? Ann Gen Psychiatry 2013; 12: 6.

5. Pessoa L. On the relationship between emotion and cognition. Nat Rev Neurosci 2008; 9: 148-58.

6. Cortina A. Neuroética: ¿las bases cerebrales de una ética universal con relevancia política? Isegoría: Revista de Filosofía Moral y Política 2010; 42: 129-48. 